\title{
Electrophoretic Profile of Protein and Isozymes in Leaf Gall Of Pongamia Pinnata (L.)
}

\author{
Richa Choudhary ${ }^{1}$, Sanjay Kumar ${ }^{2}$, Binay Kumar ${ }^{3}$ and De Ashwini Kumar ${ }^{4}$ \\ ${ }^{I}$ Department of Botany, M.S.J. College, Bharatpur, Rajasthan University, India \\ ${ }^{2}$ Department of Botany, M.S.J. College, Bharatpur, Rajasthan University, India \\ ${ }^{3}$ DRMR, Sewar, Bharatpur, Rajasthan, India \\ ${ }^{4}$ DRMR, Sewar, Bharatpur, Rajasthan, India
}

\begin{abstract}
In the present investigation the electrophoretic studies of protein and isozymes (peroxidase and polyphenol oxidase) in leaf galls of Pongamia pinnata induced by Aceria pongamiae were carried out. The results showed some variation in SDS-protein and isozymes activities banding patterns among leaf galls and normal leaf. Total twenty bands were observed in each lane of galled leaf sample, in comparison one less band was observed in normal leaf crude protein profiling of experimental plant. We observed that the intensity of protein bands was higher in galled leaf as compare to normal leaf protein. Intensity of polyphenol oxidase and peroxidase activity was found to be very high in galled leaves as compared to their normal counterparts.
\end{abstract}

Keywords: Isozymes, leaf gall, Pongamia pinnata, protein, SDS-PAGE.

\section{Introduction}

Pongamia pinnata (L.) Pierre, locally known as karanja is a drought resistance, semi-deciduous, nitrogen fixing leguminous tree belonging to the family Fabaceae. It has alternative source of energy, which is renewable, safe, non-pollutant (Yadav et al., 2011) and also has medicinal properties. Baste (2013) have been investigated the effects of pure Karanja biodiesel fuel on performance, emission, and engine wear of a 45HP, 04 cylinders, and tractor engine as compared with the baseline diesel fuel. In India, this oil was traditionally used as a fuel for cooking and in lamps, as a kerosene substitute (Sarnaik et al., 2010).

It has been estimated that approximately one-third of the world's crop is damaged by insects, mite and pests, either directly by their feeding (phytophagous) or by transmitting other disease causing agents when they feed during growth, harvest and storage of crop plants (Coulson and Witter, 1984). Gall formation is the consequence of interaction between the offensive stimulus of the insect and the defensive response of the plant. Gall formers exploit the development, morphology, physiology and chemistry of the host plant (Shorthouse and Rohfritsch, 1992). Aceria pongamiae is a highly host specific, producing varying numbers of leaf galls on Pongamia pinnata, which adversely affect the quality of leaf, in turn reducing its economical value.

The sodium dodecyl sulfate polyacrylamide gel electrophoresis (SDS-PAGE) is a technique used in biochemistry, genetics and molecular biology to separate proteins according to their electrophoretic mobility (a function of length of polypeptide chain or molecular weight as well as higher order protein folding, post translational modifications and other factors). A major advantage of electrophoresis over morphological evolution is the speed with which a large number of the test samples can be analyzed (Srivastava and Gupta, 2002). Change in plant protein profiles have been also reported in many plants (Jerez, 1998). Isozyme analysis (NATVE- PAGE) offers a raid and more reliable means for producing genetic profiles (Fingerprints) and elucidation of genetic relationships within and different taxa. These techniques are efficient tools for genetic, systematic and breeding studies (Mukhlesur et al., 2004).

\section{Materials and Methods}

Normal and galled Pongamia pinnata leaves of equal sized were collected from Keola Deo National park, Bharatpur, Rajasthan and their electrophoretic study was done. For analysis of SDS-protein, isozymes both types of leaves (normal and galled) were used. The plant leaves (normal and galled) were separately washed with running water to remove dust and powdered with motor and pestle. SDS-PAGE of protein and isozymes (peroxidase and polyphenol oxidase) were performed according to the method of Laemmli (1970) and Davis (1964) respectively.

\section{Results and Discussion}

SDS-PAGE is a simple and informative method that allows separating proteins according to their molecular weight and detecting them in comparison to molecular weight markers (Shapiro et al., 1967). It is widely used for the characterization of biological objects providing the information of their protein composition. Concerning plant objects SDS-PAGE was successfully used for the estimation of the gall diseases 
effect on plant protein (Saini and Sarine, 2012). In our study we separated proteins of normal and galled leaves of Pongamia pinnata. According to SDS-PAGE normal and galled leaves presented the variation at protein level. Total twenty bands were observed in each lane of galled leaf sample, in comparison one less band was observed in normal leaf crude protein profiling of experimental plant. The Relative mobility ( $\mathrm{Rm}$ ) values of bands were varied from 0.12 to 0.98 study stages (Fig.1). There were 2 unique bands in gall protein pattern and a unique band in normal plant leaf crude protein. Approx all bands patterns are polymorphic but 3 are monomorphic and a band had different intensity order. Monomorphic Band 1 is present in galled leaves protein and had mordant intensity $\mathrm{Rm}$ value of this band was 0.12 that was lowest $\mathrm{Rm}$ value. $2^{\text {nd }}$ monomorphic Band (Rm Value 0.18 ) was present in normal leaf protein lane, it has very low intensity. $3{ }^{\text {rd }}$ monmorphic Band (Rm Value 0.239 ) was also observed into galled leaf protein but it also had very low intensity. Band $4^{\text {th }}$ (Rm Value 0.521) was present in both of leaf sample but it had difference in intensity, the intensity of band was less in normal leaves protein as compare to galled leaves protein. Michelle et al., (2011) was also found the similar results that, the protein concentration was higher in galls of Bauhinia brevipes Vogal (Fabeace) than in any other tissues.

The electrophoretic studies revealed one peroxidase band in galled leaves whereas two in normal leaves. The Relative mobility $(\mathrm{Rm})$ values in galled leaves were 0.23 whereas in normal ones 0.26 and 0.86 . Intensity of peroxidase activity was found to be very high in galled leaf as compared to that of normal leaf (Fig. 2 ). The electrophoretic studies showed that one polyphenol oxidase band in galled leaves whereas one in normal leaves. The Relative mobility $(\mathrm{Rm})$ values in galled leaves were 0.22 whereas in normal ones 0.25 . Intensity of polyphenol oxidase activity was found to be very high in galled leaf as compared to that of normal leaf (Fig. 3). Maraite (1973) reported that one of the isozymes of polyphenol oxidase of an infested host was of pathogen origin. Whether or not, the pathogen itself was contributed directly to increase polyphenol oxidase activity in the host by contaminating some of the isozymes.

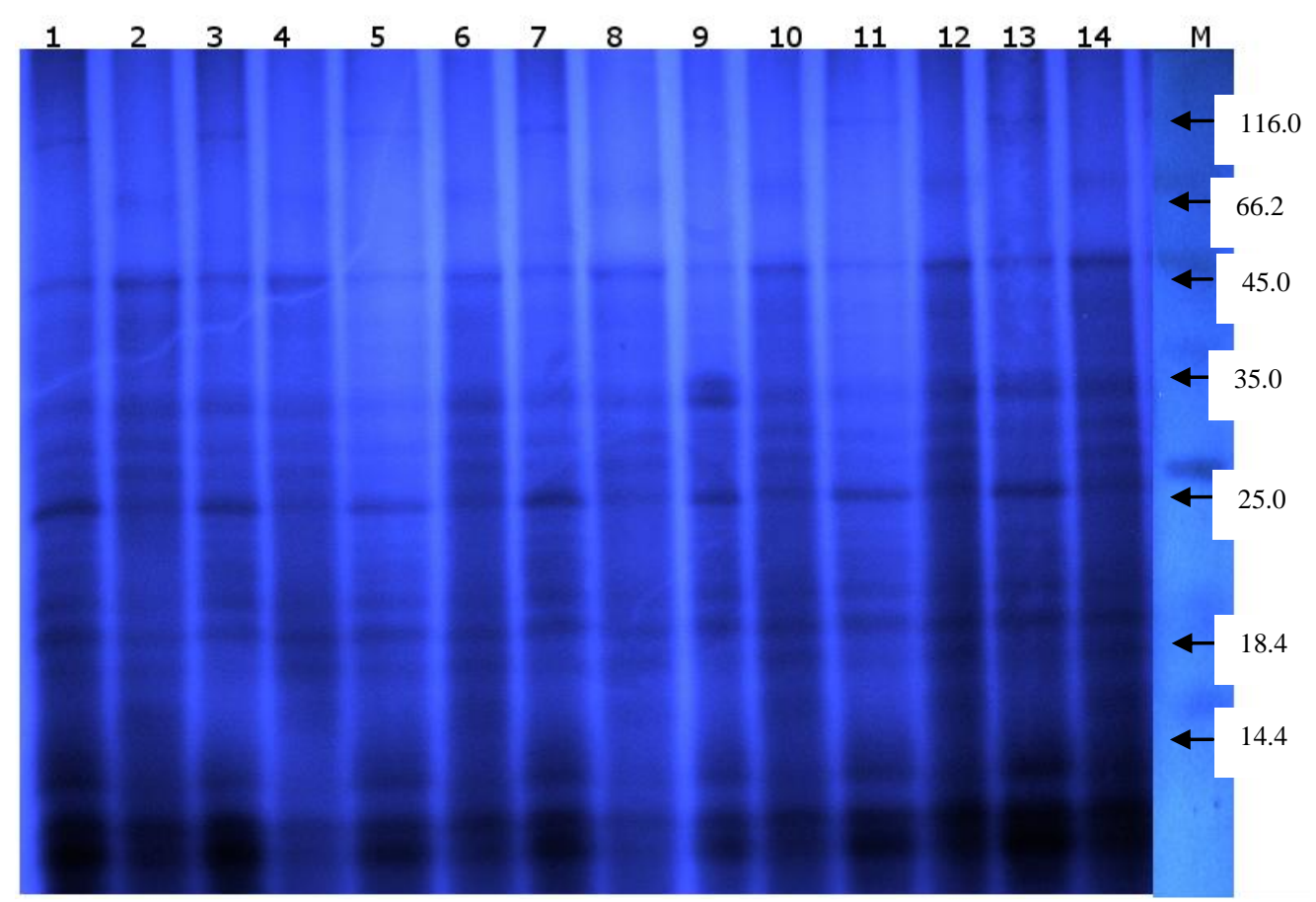

Fig. 1: electrophoretic pattern of proteins of normal and galled leaves of Pongamia pinnata.(Lane 1, 3, 5, 7,9,11 and 13 represent galled leaves proteins, Lanes 2, 4, 6, 8, 10, 12 and 14 represent normal leaves proteins and Lane $\mathrm{M}$ represents relative molecular weights (MW) of protein standards.). 

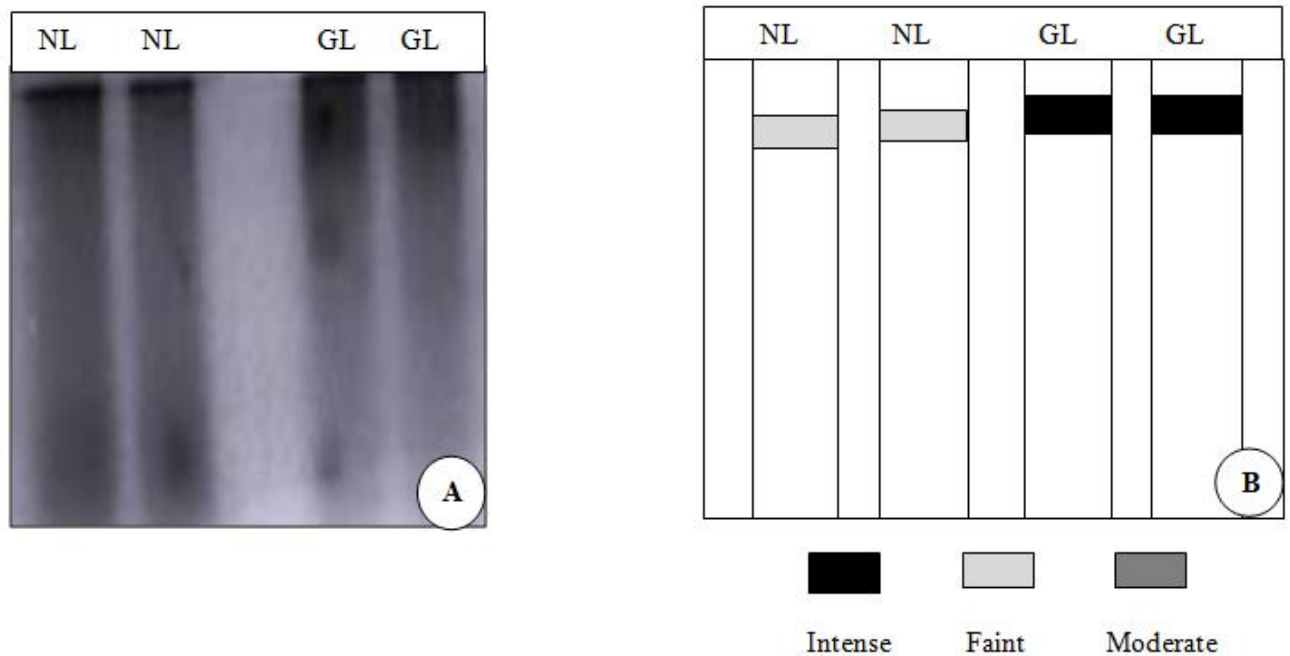

Fig. 2: (A) banding pattern of peroxidase isozyme by PAGE; (B) zymogram of isozyme profile of normal and galled leaves of Pongamia pinnata. (NL= normal leaves; $\mathrm{GL}=$ galled leaves).
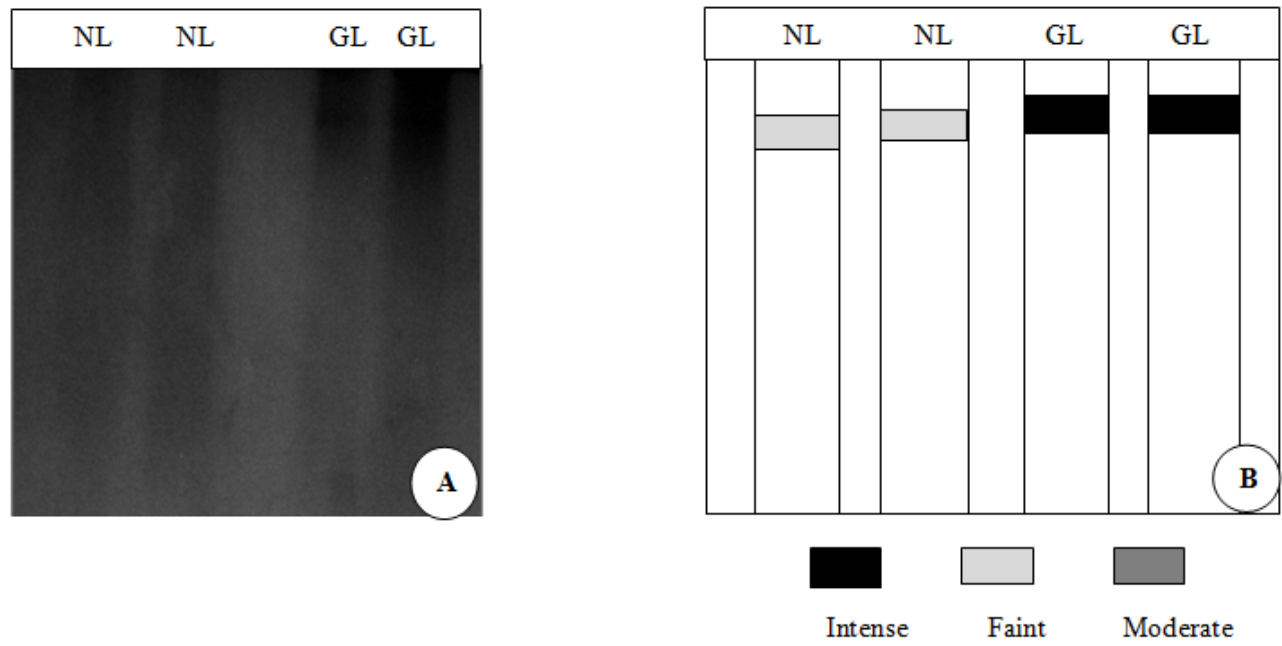

Fig. 3: (A) banding pattern of polyphenol oxidase isozyme by PAGE; (B) zymogram of isozyme profile of normal and galled leaves of Pongamia pinnata. ( $\mathrm{NL}=$ normal leaves; GL= galled leaves).

\section{Conclusion}

The intensity of proteins, peroxidase and polyphenol oxidase isozymes were higher in galled leaves as compare to normal counterparts of Pongamia pinnata. It can be concluded that due to interaction between insect and plant leaf tissue certain physiological and biological changes occur which leads to cell overgrowth in the form of gall formation take place, generation of number of cells requires high amount of protein so normal and galled leaves showed higher difference in protein concentration. Peroxidases and polyphenol oxidases are involved in defense mechanism towards the pathogen thereby these were found higher in galled leaves as compared to normal leaf.

\section{Reference}

[1] R.D. Yadav, S.K. Jain, S. Alok, S.K. Prajapati and A. Verma, Pongamia pinnata: An overview. IJPSR, 2(3), 2011, 494-500.

[2] S.V. Baste, Emission Characteristics of Pongamia pinnata (Karanja) Biodiesel and Its Blending up to $100 \%$ in a C.I. Engine, Research J. of Agri. and Forestry Sci., 1(7), 2013, 1-5.

[3] J. Sarnaik, A. Godbole, S. Andpunde, Integrating high conservation value native species into biofuel production for conservation and sustainable use of biodiversity, Applied Environmental Research Foundation (AERF), India, 2010.

[4] R.N. Coulson and J.A. Witter, Forest Entomology: Ecology and Management (John Wiley and Sons, New York, 1984 ) 669.

[5] J.D. Shorthouse and O. Rohfritsch, Biology of insect induced galls, Edited by J.D. Shorthouse, O. Rohfritsch (Oxford University Press, New York, Oxford, 1992) 285.

[6] S. Srivastava and P.S. Gupta, SDS and native PAGE protein profile for identification and characterization of elite sugarcane genotypes, Sugar Tech., 4, 2002, 143-147.

[7] M.I. Jerez, Response to two-maize inbred lines to chinch bug feeding. M.S. Thesis, Mississippi State Univ., Mississippi, 1982

[8] R.M. Mukhlesur, Y. Hirata and S.E. Alam, Genetic variation within Brassica rapa cultivars using SDS-PAGE for seed protein and isozyme analysis, Journal of biological Sciences, 3 4(2), 2004, 239-242. 
[9] U.K. Laemmeli, Cleavage of structural proteins during the assembly of the head of bacteriophase T4, Nature 27, 1970, 680-685.

[10] B.J. Davis, Disc Electrophoroesis, II, Method and application to human serum proteins, Ann. Ny. Acad. Sci., 121, 1964, $404-427$.

[11] A.L. Shapiro, E. Vinuela and J.V. Maizel, molecular weight estimation of polypeptide chain by electrophoresis in SDSPolyacrylamide gels, Biochem. Biophys. Res. Commun., 28(5), 1967, 815-820.

[12] D. Saini and R. Sarin, SDS-PAGE analysis of leaf galls of Alstonia scholaris (L.) R.Br., Journal Plant Pathol. Microb., 3(2), 2012,121 .

[13] H. Maraite, Changes in polyphenol oxidases and peroxidases in muskmelon (Cucumis melo L.) infected by Fusarium oxysporum f. sp. Melinis, Physiol. Pl. Path., 3, 1973, 29-49.

[14] L.D. Michelle DE, E.G. Vasconcelos, A.C.R.G. Maia, A.N.G. Michelia, R.M. Santos ISAIAS, G.L. Goncalaves Soares, J.C. Santos and G.W. Fernandes, Protein content and electrophoretic profile of insect galls on susceptible and resistant host plants of Bauhinia brevipes Vogel (Fabaceae), Aust. J. of Botany, 59(6) 2011, 509-514. 